\title{
EVOLUCIÓN DEL CONTROL DE CONVENCIONALIDAD
}

\author{
ROSALÍA BOHÓRQUEZ ESCOBAR ${ }^{1}$
}

REsumen: Derivado de las reformas constitucionales de dos mil once, todo el sistema jurídico se transformó, surgen nuevos paradigmas para el orden constitucional tal como la interpretación conforme derivada del artículo $1^{\circ}$ de la Norma Fundamental. Esa nueva visión dirige (y obliga) a los operadores del derecho a realizar de manera habitual el control convencional, por ello, deviene necesario analizar cómo ha evolucionado esta interpretación conforme, lo que podemos realizar a través de la visión de los jueces, quienes son los que harán efectivos los derechos contenidos en los instrumentos normativos de orden nacional e internacional.

PALABRAS CLAVE: interpretación conforme, control de convencionalidad.

ABSTRACT: Derived from constitutional reforms on two thousand eleven, all legal system was transformed, new paradigms appear to the constitutional order such as the interpretation according to the Constitution originated in its article $1^{\text {st }}$. This new vision guide (and obligate) judges as well as advocates to implement the conventional control in a habitual way, therefore, it's necessary to analyze how this interpretation has evolved though judges perspective, whose will enforce the rights contained in national and international norms.

KEYWORDS: interpretation according to the Constitution, conventionality control.

SUMARIO: I. Introducción; II. Origen del control de convencionalidad; III. Interpretación conforme del artículo $1^{\circ}$ Constitucional; IV. Naturaleza del control de convencionalidad; V. Aplicación del control de convencionalidad; VI. Conclusiones; VII. Fuentes de Consulta.

1 Alumna de la maestría en derecho con inclinación a constitucional de la Universidad Nacional Autónoma de México, con sede en Guadalajara, Jalisco. <rosoax@yahoo.com.mx> 


\section{InTRODUCCIÓN}

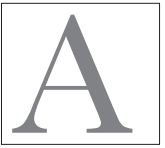

través de este trabajo se pretende analizar cómo se ha transformado la interpretación del control convencional desde el punto de visto de la efectividad; para ello, es necesario observar primeramente cómo surge aquél.

En los capítulos siguientes, se abordará la forma en que la Corte Interamericana de Derechos Humanos, a través de sus resoluciones, fue introduciendo el tema y particularmente en el caso que atañe al estado mexicano; esto es, el caso Radilla Pacheco Vs Estados Unidos Mexicanos, pues es éste el punto a partir del cual surge la reforma constitucional que a su vez da origen a la transformación del orden jurídico mexicano.

En seguida, se analiza la interpretación conforme y pro persona, que emerge del artículo $1^{\circ}$ de la Carta Magna, que a decir de José Luis Caballero Ochoa, constituye el corazón mismo de la reforma constitucional.

Posteriormente, se describe la naturaleza del control de convencionalidad, donde ya inmersos en el tema, podemos advertir quienes son los operadores del derecho encargados de realizar el control de legalidad en el ámbito supranacional; esto es, el estudio de los derechos humanos con base en las obligaciones internacionales del estado.

Apoyados en los argumentos derivados de los anteriores conceptos, se pretende destacar con criterios jurisprudenciales, la manera en que los juzgadores han tomado conciencia de los principios que conforman el actual paradigma constitucional y es ahí donde veremos si ha ocurrido o no una transformación en la interpretación del control convencional.

\section{il. Origen del control de convencionalidad}

Para responder al cuestionamiento de cómo surge el control convencional, debemos remontarnos a las resoluciones emitidas por la 
Corte Interamericana de Derechos Humanos, en las cuales se inicia el pronunciamiento sobre el tema de convencionalidad.

A partir de dos mil tres, se utiliza por primera vez tal expresión, así lo narra Eduardo Ferrer Mac-Gregor, ${ }^{2}$ que fue Sergio García Ramírez, quien la utilizó en un importante voto concurrente en el caso Myrna Mack Chang vs Guatemala, resuelto el veinticinco de noviembre de dos mil tres, por la Corte Interamericana de Derechos Humanos, en el cual indicó que la tarea de la corte se asemeja a la que realizan los tribunales constitucionales, pues estos analizan los actos impugnados a la luz de las normas, los principios y los valores de las leyes fundamentales; mientras que la Corte Interamericana analiza los actos que llegan a su conocimiento en relación con normas, principios y valores de los tratados en los que funda su competencia contenciosa; razón por la cual, si los tribunales constitucionales controlan la 'constitucionalidad', el tribunal internacional de derechos humanos resuelve acerca de la 'convencionalidad' de esos actos.

Más adelante, en la resolución dictada para el caso Almonacid Arellano vs Chile, en el año dos mil seis, es el Pleno de ese órgano colegiado internacional quien recurre a la expresión 'control de convencionalidad', aunque otorgándole una dimensión diferente, pues la utiliza a manera de una fuerza expansiva de su jurisprudencia hacia todos los jueces de los estados que han reconocido su jurisdicción, ${ }^{3}$ ya que determina la obligación legislativa en sede interna de adoptar disposiciones de conformidad con la Corte Americana de Derechos Humanos de carácter obligatorio para el Poder Judicial.

En efecto, determina el deber de adecuación del orden interno a través de i) la supresión de las normas y prácticas de cualquier

2 Eduardo Ferrer Mac-Gregor, El Control Difuso de Convencionalidad en el Estado Constitucional. Disponible en: Héctor fix-Zamudio y Diego Valadez (coords.), Formación y Perspectivas del Estado en México, Universidad Autónoma de México, México, Instituto de Investigaciones Jurídicas, 2012, p. 174.

3 Ibidem p. 175. 
naturaleza que entrañen violación a las garantías previstas en la convención y ii) la expedición de normas y el desarrollo de prácticas conducentes a la efectiva observación de dichas garantías. Por tanto, aun y cuando en ese caso se alegó que la ley de amnistía no se había aplicado en los últimos años por los jueces de esa nación, la Corte consideró que por tratarse de una norma vigente en el orden jurídico nacional, se transgredían las obligaciones convencionales. ${ }^{4}$

Con mayor claridad, se puede apreciar lo anterior de la manera siguiente: frente a la resolución de un caso y ante la existencia de normas que resultan contrarias a la Convención Americana o de tal modo inexistentes acorde a las previstas por la convención, el poder judicial de los estados miembros se encuentra obligado, de acuerdo con lo dispuesto por el artículo 1.1. del propio organismo internacional, de abstenerse en aplicar cualquier normativa contraria a ella.

Para nuestro país, resultó obligatorio el "uso" de este nuevo control, a partir de a) las cuatro sentencias condenatorias al estado mexicano, donde expresamente se refieren a este deber por parte de los jueces y órganos vinculados a la administración de justicia en todos los niveles, para ejercerlo; b) a lo dispuesto en los artículos $1^{\circ}, 2^{\circ}$ y 29 de la Convención Americana de Derechos Humanos (relacionados con la obligación de respetar los derechos, adoptar disposiciones de derecho interno y normas de interpretación más favorable); c) a lo dispuesto en los artículos 26 y 27 del Convenio de Viena sobre el Derecho de los Tratados (1969)-concernientes al pacta sunt servanda y no invocación del derecho interno-; y d) a la aceptación expresa de este tipo de control por la Suprema Corte de Justicia de la Nación, como parte importante del cumplimiento de

4 María Carmelina Londoño Lázaro, El Principio de Legalidad y el Control de Convencionalidad de las Leyes: Confluencias y Perspectivas en el Pensamiento de la Corte Interamericana de Derechos Humanos, México, Boletín Mexicano de Derecho Comparado, nueva serie, año XLIII, núm., 128, 2010, pp. 802 y 803. 
la sentencia de la Corte Interamericana de Derechos Humanos en el caso Radilla Pacheco, al conocer el expediente Varios 912/2010. ${ }^{5}$

Por su trascendencia, conviene detenernos en el año dos mil nueve, concretamente en la sentencia dictada el veintitrés de noviembre, la Corte Interamericana de Derechos Humanos, respecto al caso Radilla Pacheco vs Estados Unidos Mexicanos, en la cual se condena a este último por su responsabilidad por la violación de los derechos a las garantías judiciales y a la protección judicial, reconocidos en la Convención Americana sobre Derechos Humanos y en la Convención Interamericana sobre Desaparición Forzada de Personas, en perjuicio de Tita, Andrea y Rosendo, todos de apellidos Radilla Martínez.

Todo lo anterior, al haber incumplido adoptar disposiciones de derecho interno establecido en el artículo 2 de la Convención Americana sobre Derechos Humanos, en relación con los artículos I y III de la Convención Interamericana Sobre Desaparición Forzada de Personas, respecto de la tipificación del delito de desaparición forzada de personas.

Esa resolución marca el punto de partida para que el Poder Judicial de la Federación iniciara una nueva etapa en el desarrollo de sus resoluciones. Constituye un parteaguas para los operadores del derecho, porque a partir de esa decisión, los tribunales del estado mexicano se obligaron no solo a observar dentro de sus resoluciones tratados internacionales firmados por el mismo si no además, a la interpretación de dichos ordenamientos.

Veamos porqué se dice lo anterior. La corte interamericana condenó al estado mexicano a lo siguiente:

En relación con las prácticas judiciales, este tribunal ha establecido en su jurisprudencia que es consciente de que los jueces y tribunales

5 Eduardo Ferrer Mac-Gregor, Interpretación conforme y control difuso de convencionalidad el nuevo paradigma para el juez mexicano. Disponible en: Carbonell, Miguel y Salazar, Pedro (coords). La Reforma Constitucional de Derechos Humanos. Un nuevo paradigma, México, Porrúa, 2012, pp. 340 y 341. 
internos estén sujetos al imperio de la Ley y, por ello, están obligados a aplicar las disposiciones vigentes en el ordenamiento jurídico. Pero cuando un Estado ha ratificado un Tratado Internacional como la Convención Americana, sus jueces, como parte del aparato del Estado, también están sometidos a ella, lo que les obliga a velar porque los efectos de las disposiciones de la Convención no se vean mermados por la aplicación de leyes contrarias a su objeto y fin, que desde un inicio carecen de efectos jurídicos. En otras palabras, el Poder Judicial debe ejercer su control de convencionalidad ex oficio entre las normas internas y la convención Americana, evidentemente en el marco de sus respectivas competencias y de la regulaciones procesales correspondientes. En esta tarea, el Poder Judicial debe tener en cuenta no solamente el tratado, sino también la interpretación que del mismo ha hecho la Corte Interamericana de Derechos Humanos, intérprete último de la Convención Americana. ${ }^{6}$

Esa consideración es la que motivó la modificación de todo el aparato jurídico mexicano, pues es en dos mil once, en que, al dar cumplimiento a esa resolución, se materializa su contenido, trasladando la alta responsabilidad de las autoridades de adecuar el sistema normativo nacional al de corte internacional ya sea interpretando o bien inaplicando las leyes contrarias a su objeto y fin, cuando así sea necesario.

Bajo ese nuevo esquema del planteamiento normativo, los juzgadores tienen ante sí no solo la obligación de aplicar la ley nacional, sino además, la encomienda de realizar una interpretación convencional, al comprobar en cada una de sus sentencias que la norma que invoquen como fundamento a su decisión al resolver un caso en concreto, es compatible con el organismo internacional, pues de no ser así, ese proceder correspondería a la aplicación de una ley inconvencional, lo que traería consigo responsabilidad al estado por violentar una norma internacional contenida en un tratado al cual el estado mexicano se obligó a cumplir.

6 Guillermo Pacheco Pulido, Control de Convencionalidad, México, Editorial Porrúa, 2012, pp. XXIII, XIV y 1. 
La exigencia es mayúscula, pues ante una desatención de tal naturaleza, no es el órgano de poder el responsable del olvido, sino directamente el propio estado a quien se fincarán, en su caso, las responsabilidades relacionadas con tal incongruencia.

Para enfrentar esta nueva visión de los derechos humanos, se reformó el artículo $1^{\circ}$ de la Constitución Federal.

III. I NTERPRETACIÓN CONFORME DEL ARTÍCULO $1^{\circ}$ CONSTITUCIONAL

El artículo invocado establece, en la parte que interesa, lo siguiente:

Artículo $1^{\circ}[\ldots]$

Las normas relativas a los derechos humanos se interpretarán de conformidad con esta Constitución y con los tratados internacionales de la materia favoreciendo en todo tiempo a las personas la protección más amplia.

La porción normativa transcrita, estatuye uno de los principios más trascendentes para el sistema jurídico, la "interpretación conforme", porque con este estándar de interpretación, se potencializan los derechos humanos para ser protegidos desde la primera instancia y no hasta la última.

La figura de la "interpretación conforme", se considera aquella en la que todas las normas relativas a derechos humanos y del orden jerárquico que sea, deberán interpretarse a la luz de la propia Constitución y de los tratados internacionales en la materia. ${ }^{7}$

Ciertamente, la interpretación conforme tiene tal relevancia que se puede decir, se trata del corazón mismo de la reforma constitucional, ${ }^{8}$ pues a diferencia de otros modelos interpretativos, en

7 Miguel Carbonell, El abc de los Derechos Humanos y del Control de Convencionalidad, México, Porrúa, Universidad Nacional Autónoma de México, 2015, p. 95.

8 José Luis Caballero Ochoa, Disponible en José Ramón Cossío Díaz (coord.), Constitución Política de los Estados Unidos Mexicanos comentada, Tomo I, México, Tirant lo Blanch, 2017, p. 59. 
nuestro país, serán la Constitución y los tratados internaciones los referentes para la interpretación, lo cual no es cosa menor, porque entonces, bajo esos parámetros se tiene a la Carta Magna como un documento que reconoce y protege los derechos humanos, situación que no ocurre con otras constituciones.

Derivado de lo anterior, tanto la Constitución como los tratados internacionales de los que México es parte, conforman el llamado bloque de constitucionalidad, porque en ese ejercicio interpretativo se acudirá a todas aquellas normas que integran el sistema normativo (Constitución, tratados internacionales, legislación federal y local), lo que se traduce en la incorporación de un cuantioso cuerpo jurídico no solo de origen internacional, sino también de criterios de aplicación e interpretación propios de derecho internacional de los derechos humanos.

Es pues la interpretación conforme el medio por el cual las normas relativas a los derechos humanos, en su carácter de estándares de mínimos, son objeto de una remisión hacia la Constitución y a los tratados internacionales a efecto de obtener de ellas su aplicación más eficaz, ${ }^{9}$ de ahí que se considere que la interpretación puede generarse de la ley nacional al tratado internacional o viceversa, logrando así, una pauta protectora de mayor amplitud.

Más claramente podemos deducir lo anterior al desentrañar la naturaleza jurídica de la interpretación conforme, pues esta se concibe como un principio de corte constitucional que obliga a todas las autoridades a interpretar las normas inferiores de derechos humanos buscando la concordancia, armonización y compatibilidad más cercana a la norma constitucional, para evitar la expulsión de normas por la simple sospecha de inconstitucionalidad. ${ }^{10}$

9 Ibidem, p. 60.

10 Pedro Antonio Enríquez Soto, La interpretación conforme y su impacto en los jueces mexicanos. Cuestiones constitucionales. Revista mexicana de derecho constitucional, Num. 32, México, enero-junio 2015, pp.119 y 120. 
En esa virtud, los tratados internacionales se constituyen ahora como verdadera fuente del derecho interno y el sistema jurídico mexicano amplía la interpretación de las normas de derechos humanos.

Ahora bien, en la época del nacimiento del invocado principio constitucional, surgen voces que se avocan a desentrañar lo que había de afrontarse ante la nueva concepción y respeto hacia los derechos humanos por los operadores del derecho.

Guillermo Pacheco Pulido, consideró en dos mil doce, que no podían tenerse como criterios orientadores las resoluciones de la Corte Interamericana de Derechos Humanos, si estos resultaban vinculantes para los Poderes de la Unión; ${ }^{11}$ se cuestiona sobre el alcance del artículo 133 de la Constitución Política de los Estados Unidos Mexicanos en relación a la jerarquía de todos los tratados, pues el artículo $1^{\circ}$ de la Constitución solo da el nivel de Constitución a los Tratados Internacionales que se refieren a derechos humanos y no a otros; plantea la aplicabilidad del control difuso a través de jueces o autoridades locales no federales, así como la nueva concepción de control difuso frente al constitucionalismo moderno y al nuevo periodo que jurisprudencialmente se atendía, esto es, la décima época, quedando obsoleta la interpretación que de control difuso se había emitido con antelación.

En la actualidad, después de un periodo de ejercicio-adaptación-entendimiento, se puede decir que el propósito de tal actividad interpretativa será, a consideración de José Luis Caballero Ochoa, ${ }^{12}$ dinamizar los aspectos que conforman el bloque de constitucionalidad: los elementos constitucionales, los elementos convencionales y la jurisprudencia de cada uno de esos ámbitos normativos. Refiere que la interpretación conforme debe ser entendida como un pará-

\footnotetext{
11 Op. cit., pp. 2 y 3.

12 José Luis Caballero Ochoa, op. cit., p. 62.
} 
metro de compatibilidad entre normas de origen nacional e internacional, no solo como una ausencia de contradicción entre ambas.

Es un planteamiento que liga normas para la ubicación de cada derecho fundamental.

Bajo la óptica de la Suprema Corte de Justicia de la Nación, se acude a la interpretación conforme, para:

a) Integrar el derecho, pues primero se acude a la Constitución y luego a los tratados para su complementación, por si aquella no alcanza, no es clara o es insuficiente.

b) Debe seguir una secuencia; como un deber de todas las autoridades del estado mexicano, la elección de los jueces, respecto de interpretaciones judiciales acorde a la Constitución y los tratados internacionales y por último la inaplicación en el caso de que no sea posible armonizar las normas.

c) La interpretación conforme parte de la presunción de constitucionalidad de las normas. ${ }^{13}$

De lo expuesto tenemos que en el ejercicio interpretativo se obtenga lo siguiente: la validez de la norma, su compatibilidad con el sistema normativo al que se expuso o su inconstitucionalidad y la inaplicación de la norma; aspecto este último que se considera de alta atención y como fin último de interpretación, porque lo que se pretende no es evidenciar un deficiente sistema normativo, sino alcanzar en su mayor medida, una interpretación acorde con los estándares de los derechos humanos.

Por otro lado, en esta transformación de orden constitucional, se incorpora el principio de interpretación pro persona, muy conocido en el ámbito internacional de los derechos humanos y en los tribunales internacionales de la misma naturaleza, pero novedoso para el sistema normativo mexicano, por virtud de la aludida reforma

13 op. cit., p. 62. 
constitucional; el cual trae consigo el desarrollo de nuevos criterios interpretativos sobre derechos humanos, concibiéndose así, a través de la reforma a este precepto legal una relación entre el estado y las personas y grupos, orientada a ampliar su ámbito de protección. ${ }^{14}$

Esos criterios serán extraídos de sentencias, resoluciones, informes, observaciones generales, opiniones consultivas y demás documentos provenientes de organismos internacionales, lo que se constituye como un cuerpo normativo amplio y extenso dirigido a todos los operadores del derecho.

Pues bien, el principio pro persona alude a que cuando existan distintas interpretaciones posibles de una norma jurídica, deberá elegirse aquella que proteja con mayor amplitud al titular de un derecho humano. También, en esa concepción del invocado principio, debe considerarse que, cuando en un caso concreto se puedan aplicar dos o más normas jurídicas, el intérprete debe elegir aquella que proteja de mejor manera a los titulares de un derecho humano. ${ }^{15}$

Es así que el principio pro personae es un criterio de interpretación favorable al hombre, al constituir una guía para el operador del derecho, quien tiene a su cargo seleccionar la interpretación de la norma que mejor tutele el derecho humano de que se trate con objeto de obtener la más amplia protección del derecho en cuestión.

La elección de aplicación del principio tiene dos variables, una relacionada con la preferencia interpretativa, consistente en seleccionar la interpretación que mejore y amplíe un derecho fundamental; esto es, cuando incluya el mayor número de sujetos protegidos por el derecho. Y otra relacionada con la elección de la norma, donde

14 Luis Daniel Vázquez y Sandra Serrano, Los principios de universalidad, interdependencia, indivisibilidad y progresividad. Apuntes para su aplicación práctica. Disponible en: Miguel Carbonell y Pedro Salazar, La Reforma Constitucional de Derechos Humanos un nuevo paradigma, México, Porrúa, 2012, p. 135.

15 Miguel Carbonell, El abc de los Derechos Humanos y el Control de Convencionalidad...op cit., p. 97 
el operador del derecho elegirá aquella que sea mas favorable a la persona, sin tomar en consideración la jerarquización de normas.

Acorde con los criterios interpretativos mencionados, puede decirse que en ambos casos el operador del derecho, ya sea interpretando o eligiendo la norma adecuada, buscará y optará por aquella que proporcione la protección más amplia del derecho humano en cuestión. Así en el supuesto de que un mismo derecho fundamental esté reconocido en dos fuentes supremas internacionales, la elección de la norma que se aplicará deberá atender a criterios de favorabilidad $^{16}$ del individuo.

Este cambio de paradigma comprende también un nuevo corpus iuris más amplio no solo al ámbito interamericano y su jurisprudencia, sino a todos los derechos humanos previstos en los tratados internacionales y criterios interpretativos que emitan los órganos que se encuentren legitimados para sustentar un criterio interpretativo sobre derechos humanos.

Cuando apenas se vislumbraba el nacimiento del control convencional, se asimilaba el camino para recorrer de los jueces al interpretar los derechos humanos, considerando el artículo $1^{\circ}$ constitucional como la principal herramienta para lograr la apertura del derecho nacional al derecho internacional de los derechos humanos. Eduardo Ferrer Mac-Gregor, equipara al precepto legal a una llave de acceso a un territorio novedoso y de amplio espectro, pues se concibe a nivel de rango constitucional a los derechos humanos previstos en cualquier tratado internacional. ${ }^{17}$

De ese modo es que el artículo $1^{\circ}$ se vislumbró en el arma más eficaz para lograr una efectiva protección de los derechos humanos, pues mientras en el primer párrafo se establecía el bloque

16 "PRINCIPIO PRO PERSONA. CRITERIO DE SELECCIÓN DE LA NORMA DE DERECHO FUNDAMENTAL APLICABLE.”, Tesis aislada XIX/2011.

17 Eduardo Ferrer Mac-Greg, Disponible en: Miguel Carbonell y Pedro Salazar (coords.), La reforma constitucional de derechos humanos un nuevo paradigma... Op. cit., pp. 344 y 345 . 
constitucional, en el segundo se fijaba la cláusula de interpretación conforme, que aunado al principio pro persona, también contenido en ese mismo párrafo, se convierten no solo en guía, sino en una amalgama coherente de instrumentos jurídicos para maximizar la interpretación de normas en derechos humanos.

Por tanto, podemos decir que México cuenta con un modelo de protección de las personas y sus derechos humanos (incluyendo las correspondientes garantías), que imponen a las y los operadores jurídicos (desde la academia, la judicatura, el litigio, el activismo, etcétera) la necesidad de lograr un adecuado entendimiento de las diferencias, similitudes y vasos comunicantes que existen entre el derecho constitucional y el derecho internacional. ${ }^{18}$

\section{iv. Naturaleza Del CONTROL DE CONVENCIONALIDAD}

Para ubicar la naturaleza jurídica del control de convencionalidad, conviene indicar que ésta constituye el aspecto más destacado de la reforma constitucional de dos mil once, ${ }^{19}$ porque si la interpretación conforme es el corazón de la reforma, el control de convencionalidad constituye la válvula que impulsa el ejercicio de aquella interpretación.

Se dice lo anterior al considerar que en el ejercicio del control de convencionalidad, son los juzgadores quienes cotejarán si la aplica-

18 Zamir Andrés Fajardo Morales, Control de convencionalidad. Fundamentos y alcance. Especial referencia a México. Comisión Nacional de los Derechos Humanos, México, Comisión Nacional de los Derechos Humanos, 2015, Fascículo 16, p. 105.

19 Miguel Carbonell, lo considera “...uno de sus ejes vertebradores la apertura del sistema jurídico mexicano al ordenamiento internacional, con todo lo que ello supone: recepción de los tratados e incorporación de los mismos al derecho interno con rango constitucional, pero también reconocimiento del derecho derivado de los propios tratados y de la jurisprudencia de las jurisdicciones internacionales que han sido reconocidas por el Estado mexicano, entre otras muchas cuestiones." El abc de los derechos humanos y del control de convencionalidad, Porúa-Universidad Nacional Autónoma de México, 2014, pp. 173. 
ción de una norma es congruente en relación a los tratados internacionales y, en concordancia, con los fallos y criterios de los tribunales internacionales; ${ }^{20}$ en ese ejercicio, implícitamente se incorporan al ordenamiento jurídico mexicano tratados internacionales firmados por el estado mexicano y a los cuales se encuentra obligado desde el momento de su suscripción, pues si no se considerara así; esto es, de considerarlos fuente de derecho mexicano, no existiría forma de aplicar la norma supranacional.

Así, debemos entender entonces que este principio alude a un control de legalidad en el ámbito supranacional, realizado con la finalidad de evaluar el cumplimiento de las obligaciones internacionales con base en la armonía entre la actuación del estado y las prescripciones jurídicas internacionales. ${ }^{21}$

Este concepto me parece adecuado y comprensible, pues se presenta al control de convencionalidad como una verdadera herramienta útil para el intérprete del derecho al confrontar las normas internas con las de orden internacional.

Esto es, se trata de un examen no de exclusión si no de compatibilidad que siempre debe realizarse entre los actos, normas nacionales y tratados internacionales. Más específicamente, podemos entender al control de convencionalidad como la obligación de los jueces de atender en todo tiempo, primeramente, todos los derechos humanos contenidos en la Constitución Federal, así como la jurisprudencia emitida por el Poder Judicial de la Federación, luego, los derechos humanos contenidos en tratados internacionales en los que el estado mexicano sea parte; enseguida, los criterios vinculantes de la Corte Interamericana de Derechos Humanos derivados de las sentencias en las que el estado mexicano haya sido parte y, final-

20 Guillermo Pacheco Pulido, Control de Convencionalidad. Tratados internacionales de los derechos humanos, México, Porrúa, 2012, p. XIV.

21 Felipe de Jesús Álvarez Cibrián, José de Jesús Becerra Ramírez y Jorge Humberto Benítez Pimienta, El constitucionalismo ante el control de convencionalidad, México, Porrúa, 2015, p. 87. 
mente, los criterios orientadores de la jurisprudencia y precedentes de la corte cuando el estado no haya sido parte.

Esta fue la interpretación que hizo el Pleno de la Suprema Corte de Justicia de la Nación, al resolver el asunto Varios 912/2010, relacionado con el cumplimiento del caso Radilla Pacheco vs Estados Unidos Mexicanos. ${ }^{22}$

\section{v. Aplicación del control de convencionalidad}

Frente a la abundante doctrina sobre la reforma constitucional y en particular sobre el control de convencionalidad, interpretación conforme y principio pro persona, que derivaron de la mencionada reforma constitucional, resulta conveniente destacar cual fue el proceder de la Suprema Corte de Justicia de la Nación, ante el eminente cumplimiento que debía dar a la resolución Radilla Pacheco; esto es, las directrices que fijó el Alto Tribunal ante el novedoso procedimiento de interpretación que debían seguir los jueces.

Primeramente, debe tenerse en consideración que como las resoluciones emanadas de la Corte Interamericana de Derechos $\mathrm{Hu}$ manos, son vinculantes y deben ser observadas con carácter de cosa juzgada, su cumplimiento es ineludible bajo ninguna justificación.

En ese tenor, los operadores jurídicos, a fin de afrontar ese nuevo paradigma de la interpretación, deben constatar la adecuación de las disposiciones normativas internas que apliquen específicamente en casos concretos los contenidos de la Convención Americana, así como los estándares interpretativos establecidos por la Corte Interamericana de Derechos Humanos. ${ }^{23}$

Así, es inminente la obligatoriedad a la que se encuentra vinculados los jueces en el ejercicio del control de convencionalidad, sin

22 Semanario Judicial de la Federación y su Gaceta, Décima Época, Libro III, Diciembre de 2011 , Tomo 1, registro 160526, p. 551.

${ }^{23}$ Víctor Bazán El control de convencionalidad: incógnitas, desafios y perspectivas. Citado por Felipe de Jesús Álvarez Cibrián, op. cit., p. 101. 
importar si pertenecen o no al Poder Judicial, su jerarquía, grado o especialización, pues de cualquier modo están obligados a ejercer dicho control aun de oficio.

Por tanto, podemos colegir que a partir de lo resuelto en el caso Radilla Pacheco, los jueces deben realizar de manera habitual control convencional cuando se encuentren ante la posibilidad de que normas nacionales puedan atentar contra el objeto y fin de los efectos de las fuentes emanadas del sistema interamericano de protección de los derechos humanos. ${ }^{24}$

Sin embargo, el reto que se presenta ante los jueces no se vislumbra fácil ni cómodo, porque deberá afrontar interrogantes relacionadas a cómo ejercer el control de convencionalidad al que se encuentra obligado, de dónde partir, qué parámetros elegir y qué límites se imponen ante el ejercicio de esta atribución, entre otros cuestionamientos a los que deben darse respuesta, a fin de no eludir el compromiso de interpretación.

Pues bien, para el desarrollo de ese ejercicio, el juzgador debe prepararse adecuadamente en el conocimiento de los criterios interpretativos como son la interpretación conforme y el principio pro persona, a los cuales se ha hecho alusión.

Concurre en ese adecuado desenvolvimiento del parámetro de interpretación los llamados diálogos jurisprudenciales a los que hace alusión Eduardo Ferrer Mac Gregor, suscitados con motivo de la multiplicidad de interpretaciones hechas por los juzgadores a las normas nacionales e internacionales de derechos humanos, buscando tras el debate, hacer prevalecer la interpretación que brinde a la persona la protección más amplia de sus derechos, pudiendo ser estos diálogos: internos (al interior de los propios tribunales), verticales internacionales (entre los jueces nacionales y los interamericanos); verticales internos (entre las altas jurisdicciones nacionales y los jueces domésticos); horizontales (entre jueces de la misma je-

24 Felipe de Jesús Álvarez Cibrián, op. cit., p. 108 
rarquía); paralelos (entre tribunales internacionales) y trasversales (entre tribunales internacionales y supranacionales). ${ }^{25}$

Tales aspectos constituyen un parámetro técnico-metodológico a seguir en el estudio del asunto, otro importante punto será identificar el derecho humano previsto en el instrumento internacional que en su concepto resulte infringido por el acto o la ley; seguidamente, verificará los requisitos para la recepción de un tratado internacional en México, que consiste en que el pacto se celebre por el Presidente de la República, lo aprueba el Senado y no tenga reservas o declaraciones interpretativas, cuyo objeto fuera excluir o modificar los efectos jurídicos de la disposición del tratado en su aplicación. Luego, habrá de utilizar como premisa mayor partir del principio de constitucionalidad y convencionalidad de la norma nacional, a través de una interpretación conforme armónica. ${ }^{26}$

En ese proceso de disertación, el juzgador habrá de acogerse a los criterios que la Suprema Corte de Justicia de la Nación ha emanado a ese respecto a fin de encontrar la protección más amplia.

Para ello, es conveniente acudir a la tesis de jurisprudencia de rubro "PASOS A SEGUIR EN EL GONTROL DE CONSTITUCIONALIDAD Y CONVENCIONALIDAD EX OFFICIO EN MATERIA DE DERECHOS HUMANOS", en la cual se contienen en el ejercicio del control de convencionalidad respecto a derechos humanos, los jueces deben seguir los pasos siguientes:

a) Interpretación conforme en sentido amplio, lo que significa que los jueces del país al igual que todas las demás autoridades del Estado mexicano, deben interpretar el orden jurídico a la luz y conforme a los derechos humanos reconocidos en la Constitución y en los tratados internacionales en los cuales el Estado mexicano sea parte, favoreciendo en todo tiempo a las personas con la protección más amplia; b) Interpretación conforme en sentido estricto, consiste en que cuando haya varias interpretaciones jurídicamente válidas,

25 Ibidem, p. 114.

26 Ibidem p. 117. 
los jueces deben preferir aquella que vaya acorde a los derechos humanos reconocidos en la Constitución y en los tratados internacionales en los que el estado mexicano sea parte, para evitar incidir o vulnerar el contenido esencial de estos derechos; y c) Inaplicación de la ley, cuando las alternativas anteriores no son posibles. ${ }^{27}$

En el ejercicio interpretativo que se plantea, el juzgador ve direccionado su actuar de lo más a lo menos; es decir, inicia con un catálogo de normas extenso previamente previsto en la Constitución y los tratados internacionales y de encontrar más de una adecuación normativa aplicable al caso concreto, acudirá al siguiente nivel, donde habrá de preferir la que vaya acorde a los derechos humanos en estudio, evitando vulnerar dichos derechos; empero, de no ser suficiente lo anterior, deberá inaplicar la ley; acto este último que se pretende por la doctrina como por la jurisprudencia evitar en lo posible o considerarla como fin último de una determinación, porque lo que se pretende no es el desconocimiento del derecho (que es lo que conlleva la inaplicación de una norma), sino la adecuación del sistema normativo al derecho supranacional, buscando en todo caso, la adaptación del orden jurídico interno a las normas del orden internacional.

En ese proceso de conocimiento y adaptación del contenido del nuevo criterio interpretativo y en búsqueda de fórmulas y métodos para el ejercicio adecuado del control convencional, encontramos que la Suprema Corte de Justicia de la Nación, ha emitido criterios vinculados con dicho principio, los cuales inclusive han ido variando conforme la reflexión lo permite.

Así, podemos advertir, por ejemplo, anteriormente, las sentencias de la Corte Interamericana de Derechos Humanos, derivadas de los casos en los que México fue parte, eran obligatorias en sus

27 Semanario Judicial de la Federación y su Gaceta, Décima Época, Libro III, Diciembre de 2011, Tomo 1, p. 552, registro 160525. 
términos ${ }^{28} \mathrm{y}$, al contrario, determinó que los criterios emanados de la corte trasnacional en los que el estado mexicano no era parte, corresponderían al orden de la orientación, para los jueces mexicanos cuando fueren más favorables a la persona en términos del artículo $1^{\circ}$ de la Constitución Federal. ${ }^{29}$

Esta última tesis fue muy criticada, porque "al reconocerle un criterio orientador a los criterios de la Corte IDH permite que, al resolver un caso concreto, cualquier autoridad judicial mexicana se 'oriente' en un sentido distinto al que sostiene la jurisprudencia interamericana". ${ }^{30}$

Esa tesis fue superada al resolverse la contradicción de tesis 293/2011, donde la Corte dispuso, en contraposición a la tesis anterior, que la jurisprudencia de la Corte Interamericana de Derechos Humanos era obligatoria para México, en todos los casos y no solamente cuando el país hubiere figurado como parte en el juicio. $^{31}$

No obstante, en esa propia ejecutoria, se sostiene el criterio derivado de la restricción constitucional; a saber: cuando "[...] derivado de la parte final del primer párrafo del artículo $1^{\circ}$ Constitucional, el Pleno de esta Suprema Corte de Justicia de la Nación entiende que cuando en la Constitución haya una restricción expresa al ejercicio de los derechos humanos se deberá estar a lo que indica la norma constitucional".

Interpretación con la cual, algunos autores desavienen por considerarla contraventora de lo asumido por la Convención Americana

28 Semanario Judicial de la Federación y su Gaceta, Libro III, Diciembre de 2011, Tomo 1, tesis P.LXV/2011, p. 556.

29 Semanario Judicial de la Federación y su Gaceta, Libro III, Diciembre de 2011, Tomo 1, tesis P.LXVI/2011, p. 550.

3о Miguel Carbonell, El ABC de los Derechos Humanos y del Control de Convencionalidad, op. cit., p. 173.

31 Gaceta del Semanario Judicial de la Federación, Décima Época, Pleno, Libro 5, Abril de 2014, Tomo I, página 96, registro Núm. 24985. 
de Derechos Humanos. Sin que en el caso haya sido superada por la corte nacional.

Se cuenta en esta recapitulación, el criterio contenido en la tesis 2a. CII/2016 (10a.) derivado de la interpretación que de la jurisprudencia emitida por la Corte hizo un tribunal de menor jerarquía, al pretender someterla a control convencional, pues ni por virtud de ese ejercicio interpretativo, puede desconocerse la jerarquía de los órganos del Poder Judicial de la Federación. ${ }^{32}$

Importa destacar que en esa transición sobre la interpretación convencional, si bien se obligaba a los operadores del derecho tanto federales como del orden común a realizar control de convencionalidad, esa facultad se limitó con relación a la declaratoria de inconstitucionalidad de normas, pues ese ejercicio se declaró nugatorio para los juzgadores del orden común, al considerar que esa función está supeditada a los órganos federales. ${ }^{33}$

De igual manera, encontramos en la tesis de rubro: "CONTROL DifUSO. SU EJERCICIO EN EL JUICIO CONTENGIOSO ADMINISTRATIVO”, ${ }^{4}$ limitaciones a la actividad jurisdiccional relacionada con el control convencional, pues distingue claramente, que para considerar ejercido dicho control por parte de las autoridades administrativas que regulan el procedimiento contencioso administrativo, bastará que mencione en su resolución que no advirtió violación alguna de derechos humanos para estimar realizado el control difuso de convencionalidad o de constitucionalidad, sin que sea necesario desarrollar una motivación jurídica exhaustiva; lo que se justifica en la medida de que esa actividad la realizará, en su momento, el

32 Gaceta del Semanario Judicial de la Federación, Décima Época, Libro 35, Octubre de 2016, Tomo I, p. 928, registro 2012726.

зз "CONTROL DE CONSTITUCIONALIDAD $\Upsilon$ DE CONVENCIONALIDAD (REFORMA CONSTITUCIONAL DE 10 DE JUNIO DE 2011)". Semanario Judicial de la Federación y su Gaceta, registro 2002264.

34 Gaceta del Semanario Judicial de la Federación, registro 2006186. 
Poder Judicial de la Federación, al que se considera de competencia primigenia para conocer de esos asuntos.

Tal consideración se estima contraria a las pautas que determinan el control convencional, primeramente, porque, si como se dijo, los pactos deben cumplirse por ser cosa juzgada, encontrándose los jueces obligados a velar porque los efectos de las disposiciones que contienen derechos humanos de la Constitución y de las convenciones internacionales no se vean mermados en la eficacia por la aplicación de las leyes o jurisprudencia, de acuerdo con las resoluciones dictadas por la Corte Interamericana de Derechos Humanos y el artículo $1^{\circ}$ Constitucional.

En el caso, por expresión jurisprudencial de la Corte, la instancia administrativa está ignorando tal encomienda, pues bajo la consideración de que la competencia primigenia es a nivel federal, se limita al juzgador el conocimiento de un aspecto trascendental contenido en la reforma constitucional; y no solo eso, los límites alcanzan al justiciable, porque se le coarta el acceso a una valoración que bien podría serle favorable en aras de una interpretación conforme y acorde a los parámetros fijados por la Corte Interamericana de Derechos Humanos.

No se ignoran las razones que pudieron suscitar el criterio jurisprudencial y que suponen un adecuado ejercicio de control convencional a cargo de la autoridad federal; empero, ello no justifica el deslinde de responsabilidad que corresponde a la autoridad administrativa; pues una mejor respuesta a esa situación sería la capacitación en el ámbito de los controles de interpretación conforme, pro persona, control convencional, entre otros, que emergieron con el cambio de paradigma derivado de la reforma constitucional, para que así, todos los operadores del derecho participen de esa actividad interpretativa, retroalimentando -en los términos que lo aduce Ferrer Mac Gregor-, a través de diálogos jurisprudenciales suscitados a nivel vertical interno. 
Tampoco pasa desapercibida la expresión de que el Poder Judicial de la Federación, es el competente primigenio para conocer de esos asuntos, pues de igual manera debe decirse que aunque ello resulte cierto, nos encontramos en otra etapa de evolución interpretativa de los derechos humanos, en la que no cabe esa afirmación.

\section{vi. Conclusiones}

Tratándose del control convencional establecido por la Corte Interamericana de Derechos Humanos, su aplicación y ejercicio debe corresponder siempre, de manera inicial a los juzgadores primarios, pues tal figura emana del principio de legalidad, al instaurarse con la finalidad de revisar la forma en que actúa el estado dentro del marco jurídico nacional.

La interpretación del control de convencionalidad se encuentra en evolución, es perfectible y con dirección; sin embargo, en ese devenir, convendrá ajustar aquellas interpretaciones que se encuentren alejadas de un control efectivo sobre convencionalidad.

El estado mexicano, a través de la Suprema Corte de Justicia de la Nación, no ha cumplido a cabalidad con los lineamientos implantados por la Corte Interamericana de Derecho Humanos, pues aun cuando se han emitido diversos criterios a través de los cuales se establece la posibilidad de aplicar un control de convencionalidad en los asuntos que se dirimen ante los tribunales ordinarios, lo cierto es que el máximo órgano de justicia, se ha reservado para sí su ejercicio real, en menoscabo de las garantía de legalidad y seguridad jurídica de los gobernados que requieren de la aplicación de "primera mano" del principio de convencionalidad.

Finalmente, resta destacar que la evolución del principio de convencionalidad es tangible, dado que el órgano encargado de hacerlo, mediante jurisprudencia, ha pretendido dar cumplimiento a la resolución de orden internacional; empero, ha sido insuficiente, pues no permite que en esa evolución también lo hagan las autori- 
dades del orden común, monopolizando el ejercicio e impidiendo por consiguiente la preparación de los jueces con ese propósito.

\section{Bibliografía}

Álvarez Cribrián, Felipe de Jesús et al., El constitucionalismo ante el control de convencionalidad, Porrúa, México, 2015.

Caballero Ochoa, José Luis. Disponible en Cossío Díaz, José Ramón (coord.), Constitución Política de los Estados Unidos Mexicanos comentada, Tomo I, Tirant lo Blanch, México, 2017.

Carboneld, Miguel, El abc de los Derechos Humanos y del Control de Convencionalidad, Porrúa-Universidad Nacional Autónoma de México, $2^{\mathrm{a}}$ edición, México, 2015.

Fajardo Morales, Zamir Andrés, Control de convencionalidad. Fundamentos y alcance. Especial referencia a México. Comisión Nacional de los Derechos Humanos, México, 2015, Fascículo 16.

Ferrer Mac-Gregor, Eduardo, El Control Difuso de Convencionalidad en el Estado Constitucional. Disponible en: FIX-Zamudio, Héctor y Valadés, Diego (coord.), Universidad Autónoma de México, Instituto de Investigaciones Jurídicas, México, 2012.

Ferrer Mac-Gregor, Eduardo, Interpretación conforme y control difuso de convencionalidad el nuevo paradigma para el juez mexicano. Disponible en: Carbonell, Miguel y Pedro Salazar (coords). La Reforma Constitucional de Derechos Humanos. Un nuevo paradigma, Porrúa, 2012

Londoño Lázaro, María Carmelina, El Principio de Legalidad y el Control de Convencionalidad de las Leyes: Confluencias y Perspectivas en el Pensamiento de la Corte Interamericana de Derechos Humanos, Boletín Mexicano de Derecho Comparado, nueva serie, año XLIII, núm., 128, mayo-agosto de 2010.

Pacheco Pulido, Guillermo, Control de Convencionalidad, México, Editorial Porrúa, 2012, pags. XXIII, XIV y 1. 
VÁzQuez, Luis Daniel y Sandra Serrano, Los principios de universalidad, interdependencia, indivisibilidad y progresividad. Apuntes para su aplicación práctica. Disponible en: Carbonell, Miguel y Pedro Salazar, La Reforma Constitucional de Derechos Humanos un nuevo paradigma. Porrúa, México, 2012.

\section{LEGISLACIÓN}

Constitución Política de los Estados Unidos Mexicanos.

Medios electrónicos

<https://revistas.juridicas.unam.mx/index.php/cuestiones-constitu cionales/article/view/6085/8026>.

Enriquez Soto, Pedro Antonio, La interpretación conforme y su impacto en los jueces mexicanos. Cuestiones constitucionales. Revista mexicana de derecho constitucional, Num. 32, enero-junio 2015.

Semanario Judicial de la Federación y su Gaceta. 